\title{
La tutela de prevención en los procesos por violencia familiar $^{(*)}$
}

\section{Prevention guardianship in family violence processes}

\author{
LA INSTRUMENTALIDAD, COMO UNA CARACTERÍSTICA PROPIA DE ESTAS MEDIDAS \\ ANTICIPADAS, NO SE EXTIENDE A LAS MEDIDAS DE PROTECCIÓN, PUES, SU OBJETO NO ES EL \\ DERECHO EN LITIS, SINO UN BIEN JURÍDICO COLATERALAL DEBATE, COMO ES LA INTEGRIDAD \\ DE LA PERSONA HUMANA EN TODA SU DIMENSIÓN, DE AHÍ QUE HEMOS DICHO, NO ES UNA \\ JUSTIFICANTE PARA SU DICTADO, LA EXIGENCIA DE MEDIOS DE PRUEBA QUE DEMUESTREN \\ EL RIESGO PARA SU SUPERVIVENCIA SINO QUE LA MERA ALEGACIÓN ES SUFICIENTE PARA \\ MATERIALIZAR ESA TUTELA.
}

\begin{abstract}
Resumen: En este artículo, la autora describe la importancia de las medidas de protección dictadas en los procesos de violencia familiar, a propósito de la Ley 30364. Asimismo, señala su diferencia con las medidas cautelares, siendo que las medidas de protección ofrecen tutela preventiva a las víctimas de violencia familiar. Concluye que las medidas de protección deben ser interpretadas de acuerdo a determinados principios, y su vigencia debe continuar a través de un proceso no contencioso.
\end{abstract}

Palabras Clave: Proceso de Violencia Familiar - Ley 30364 - Medidas de Protección - Tutela Preventiva - Tutela Anticipada - Violencia Familiar

\begin{abstract}
In this article, the author describes the importance of protection orders issued in domestic violence processes, in relation to Law 30364. In addition, she points out its difference with interim orders, that protection orders offer preventive protection to the victims of domestic violence. She concludes that protection orders must been interpreted according to certain principles and its validity must continue through a non-contentious process.
\end{abstract}

Keywords: Domestic Violence Process - Law 30364 - Protection Orders - Preventive Guardianship - Anticipate Guardianship - Domestic Violence

(*) Magistrada del Tribunal Constitucional del Perú. Abogada por la Universidad Nacional Mayor de San Marcos. Doctora en Derecho por la misma casa de estudios. Profesora en las siguientes universidades: Pontificia Universidad Católica del Perú, Universidad del Pacífico, Universidad de Lima, Universidad de Piura, Universidad Femenina del Sagrado Corazón y Universidad Nacional Mayor de San Marcos. Correo electrónico: mledesma@pucp.edu.pe

${ }^{* *}$ Nota del Editor: el artículo fue recibido el 30 de mayo de 2017 y su publicación fue aprobada el 16 de junio del mismo año. 
La tutela de prevención en los procesos por violencia familiar Prevention guardianship in family violence processes

\section{Preliminares}

La violencia que se ejerce contra las mujeres y demás integrantes de un grupo familiar, es una constante en nuestra vida social que viene incrementándose. Esto no deja de ser preocupante para los operadores judiciales y sobre todo para quienes están encargados de dirigir las políticas públicas para evitar o erradicar esta violencia al interior de los hogares. En ese contexto, apreciamos el informe del Instituto Nacional de Estadística e Información (INEI) que evidencia el incremento de las denuncias por violencia familiar en nuestro país. Señala que a nivel nacional, el Ministerio de la Mujer, en el año 2011 registró a nivel nacional 40,000 casos de violencia familiar y en el 2014, éste se ha incrementado a 50,400 casos $^{(1)}$.

Además, el Octavo Reporte de la Defensoría del Pueblo (Informe No. 173-2015-DP) sobre el "Feminicidio Íntimo en el Perú: Análisis de Expedientes Judiciales (2012 -2015)" señala que el $60 \%$ de los casos, las víctimas tenían o tienen hijos y/o hijas menores de edad ${ }^{(2)}$.

Frente a esta problemática se ha diseñado una respuesta legal que aparece esbozada en la Ley 30364 (En adelante,
"Ley"). Ella constituye un importante avance al dejar la sanción contra la violencia a la mujer únicamente en el contexto familiar y sancionar la violencia contra la mujer por razones de género, lo que implica que el Estado Peruano se adecúa a la Convención Belém do Pará de la que es suscriptor y con ello a los estándares internacionales sobre derechos humanos vinculados con la problemática de la mujer. El propio texto de la norma define a la violencia contra los integrantes del grupo familiar, como "toda acción u omisión que les cause muerte, daño, sufrimiento físico, sexual o psicológico y se produce dentro de una relación de responsabilidad, dependencia, confianza o poder, de parte de un o una integrante a otro u otra del grupo familiar"(3). Tienen especial protección las niñas, niños, adolescentes, adultos mayores y personas con discapacidad.

En ella se plantea algunas propuestas orientadas a reducir la criminalidad contra las mujeres y los integrantes del grupo familiar. A

(1) Señala el Informe Defensorial No. 173 que "la educación en nuestro país no garantiza ciudadanos conscientes y respetuosos del derecho a una vida libre de violencia de las mujeres. Asimismo, esta información confronta el mito o la creencia de que solo las personas con escasos niveles de instrucción son las que ejercen violencia en relación de pareja. Sin embargo, está visto que el mayor índice de agresores se concentra en los que tienen educación secundaria y superior completa". Defensoría del Pueblo, Informe Defensorial No. 173-2015-DP (Perú: Defensoría del Pueblo, 2015), 105.

Para corroborar lo que sostiene el referido Informe Defensorial, hemos encontrado el siguiente caso, donde el agresor no solo es un abogado, incluso tiene el agravante de ser un miembro del Ministerio Público. El Consejo Nacional de la Magistratura, mediante la Resolución No. 103-2016-PCNM, de fecha 7 de octubre de 2016, impuso la sanción de destitución del señor Juan Carlos Castro Álvarez, quien se venía desempeñando como Fiscal Adjunto Provincial Provisional de la Fiscalía Provincial Penal Corporativa de Ucayali, Contamana, Distrito Fiscal de Loreto, por haber agredido física y psicológicamente, en estado de ebriedad, a su conviviente Marianela Chimpa Pezo. El Informe también detalla que el Fiscal Provincial de la Fiscalía Provincial Civil y Familia de Ucayali, Contamana se apersonó inmediatamente a la Comisaría, donde recogió in situ la versión de la afectada, quien refería que momentos antes el intervenido había ingresado a su dormitorio profiriendo palabras agresivas y denigrantes, le había roto su ropa interior, jalado de los cabellos y tirado al piso, y amenazado con un cuchillo, y hacía tres días atrás la había golpeado en el lado izquierdo de la boca, pues estuvo bebiendo alcohol todos los días de la semana anterior, excepto el martes; asimismo, recogió la versión de la propietaria del lugar donde se produjeron los hechos, quien manifestó que en varias oportunidades el fiscal investigado protagonizó escándalos, siempre en estado de ebriedad, e incluso una vez rompió la ventana de su dormitorio; el informe precisa además que la agraviada pasó el reconocimiento médico en el centro de salud de Contamana y el investigado pasó el dosaje etílico y fue dejado en libertad, existiendo imágenes grabadas de los hechos.

(2) De acuerdo a diversos estudios, el impacto de la violencia en los niños y niñas implica un riesgo en su proyecto de vida, por ello, es necesario contar con políticas públicas enfocadas en la recuperación de la salud integral de los menores de edad, a fin de evitar la repetición de estos patrones de violencia. Defensoría del Pueblo, Informe Defensorial No. 173-2015-DP (Perú: Defensoría del Pueblo, 2015), 196.

(3) Véase Ley 30364 , artículo 5. 
Marianella Ledesma Narváez

través de un procedimiento especial las víctimas de violencia pueden obtener dentro de las 72 horas de formulada su denuncia, el dictado de medidas de protección por parte de los jueces especializados en Familia y además, la derivación de su denuncia hacia el Ministerio Público, a fin que proceda a la investigación que conlleve a determinar la responsabilidad penal por parte del supuesto agresor que denuncia la víctima(4). El juez de familia resuelve en audiencia oral, no solo la emisión de las medidas de protección requeridas sino que, de oficio o a solicitud de la propia víctima, también se pronuncia sobre las medidas cautelares que resguardan pretensiones de alimentos, regímenes de visitas, tenencia, suspensión o extinción de la patria potestad, liquidación de régimen patrimonial y otros aspectos conexos que sean necesarios para garantizar el bienestar de las víctimas.

En este escenario el trabajo aborda los efectos que genera para las medidas de protección, la conclusión del proceso penal. Al respecto, el artículo 23 de la Ley señala "la vigencia de las medidas dictadas por el Juzgado de Familia o su equivalente, se extiende hasta la sentencia emitida en el juzgado penal o hasta el pronunciamiento fiscal por el que se decida no presentar denuncia penal por resolución denegatoria, salvo que estos pronunciamientos sean impugnados". En el presente artículo se esboza algunos argumentos que justifican la vigencia de estas medidas de protección, más allá de la existencia o no del proceso penal.

\section{Medidas de protección y medidas cautelares}

Cuando se denuncia actos de violencia contra las mujeres y los integrantes del grupo familiar se activan una serie de mecanismos, como: (i) la indagación fiscal sobre la comisión del delito y la posible responsabilidad del supuesto agresor; (ii) la tutela cautelar que puede ejercer el juez de oficio o por solicitud de la víctima, siempre que estén orientadas a resguardar pretensiones de alimentos, régimen de visitas, tenencia, suspensión o extinción de la patria potestad, liquidación del régimen patrimonial y otros aspectos conexos que sean necesarios para garantizar el bienestar de las víctimas; y, (iii) las medidas de protección para la víctima.

\section{Tutela judicial que se activa ante la denuncia por violencia familiar}

\begin{tabular}{|c|c|c|}
\hline $\begin{array}{l}\text { TUTELA } \\
\text { CLÁSICA }\end{array}$ & $\begin{array}{l}\text { RESARCIMIENTO } \\
\text { FUNCIÓN }\end{array}$ & $\begin{array}{l}\text { 超 } \\
\text { 貓 }\end{array}$ \\
\hline $\begin{array}{l}\text { TUTELA } \\
\text { PREVENTIVA }\end{array}$ & $\begin{array}{l}\text { MEDIDAS } \\
\text { DE } \\
\text { PROTECCIÓN }\end{array}$ & 혹 \\
\hline
\end{tabular}

Estos mecanismos responden a objetos y fines diversos por más que todas ellas estén íntimamente conectados con los mismos hechos de violencia generados bajo el grupo familiar; tal es así, que cuando se remite el caso a la fiscalía penal, lo que se busca es justificar la actividad punitiva del Estado contra el agresor, bajo el agravante de haber generado esa afectación en un contexto familiar. En caso se acredite el delito y la responsabilidad penal, podría conllevar a la privación de libertad del agresor o la absolución. El otro mecanismo que se activa es la tutela cautelar, a fin de lograr que la decisión final que se pueda alcanzar en estas pretensiones sean eficaces; y por último, se promueve hacia la parte afectada mecanismos de protección, a fin de evitar que continúen los actos lesivos.

Como se puede advertir, estamos ante mecanismos de tutela, con objetos y naturaleza

(4) Véase Ley 30364, articulo 16. En el artículo 15 de la citada Ley 30364 hace referencia que las victimas pueden formular su denuncia de manera oral o escrita ante el juez, manifestando de manera sucinta los hechos de violencia. Esta denuncia no necesariamente puede realizarla de manera personal la persona perjudicada sino que puede ser asumida por cualquier otra persona en su favor, sin necesidad de tener su representación. La Ley 30364, también ha habilitado a la Defensoría del Pueblo para que pueda interponer también la denuncia a favor de la persona perjudicada por la agresión. También pueden denunciar los casos de violencia los profesionales de la salud y educación. 
disímiles. En el caso del proceso penal, la relación procesal que se entablará, tendrá como sujeto pasivo al probable agresor; en el proceso que se plantea pretensiones vinculadas a los alimentos, régimen de visitas, tenencia, suspensión o extinción de la patria potestad, liquidación del régimen patrimonial tendrá como sujeto activo de la medida cautelar al titular del derecho material cuya tutela judicial se invoca; y en el caso de las medidas de protección, estas se orientaran a brindar medidas de tuición a favor de quien denuncia los actos de violencia, y no solo para quien denuncia, sino incluso para otras personas que bajo el entorno familiar también sean pasibles de dichas agresiones. Este trabajo abordará este último supuesto, las medidas de protección, sin embargo, considero necesario diferenciar éstas de las medidas cautelares.

Un antecedente cercano a estas medidas, es el que consigna el artículo 677 del Código Procesal Civil (en adelante, "CPC"), que señala:

"Cuando la pretensión principal versa sobre separación, divorcio, patria potestad, régimen de visitas, entrega de menor, tutela y curatela, procede la ejecución anticipada de la futura decisión final, atendiendo preferentemente al interés de los menores afectados con ella. Si durante la tramitación del proceso se producen actos de violencia física, presión psicológica, intimidación o persecución al cónyuge, concubino, hijos o cualquier integrante del núcleo familiar, el juez debe adoptar las medidas necesarias para el cese inmediato de los actos lesivos, sin perjuicio de lo dispuesto en el artículo 53".

Este texto hace referencia a la tutela anticipada, para lo cual la medida que se dicta debe ser el reflejo de una alta probabilidad de la existencia del derecho invocado y la necesidad ineludible de anticipar los efectos de la sentencia final. Además, se acoge a las medidas de protección, las que difieren de la medida anticipada. La medida de protección se dicta, si durante la tramitación del proceso se producen actos de violencia física, presión psicológica, intimidación o persecución al cónyuge, concubino, hijos o cualquier integrante del núcleo familiar y no requieren de contracautela a diferencia de las medidas anticipadas. En atención a ello, el juez debe adoptar las medidas necesarias para el cese inmediato de los actos lesivos, sin perjuicio de que el propio juez ejerza facultades coercitivas como las sanciones pecuniarias o la detención por veinticuatro horas de quien resiste su mandato sin justificación, como lo señala expresamente el artículo 53 del CPC, pues no hay nada más perjudicial para la majestad de la justicia que la desobediencia a las órdenes y mandatos judiciales.

Si bien las medidas de protección tienen destinatarios o beneficiados al cónyuge, concubino, hijos o cualquier integrante del núcleo familiar, ellas encierran a la vez medidas conminatorias dirigidas a la parte que provoca la agresión, que no necesariamente puede ser la parte demandada sino que también puede extenderse a la propia demandante. Las medidas conminatorias no están orientadas estrictamente hacia el demandado, sino a las partes y terceros que participen en el proceso.

Las medidas de protección aparecen también reguladas en la ley especial sobre violencia familiar y han sido materia de la temática del Pleno Jurisdiccional Superior Regional de Familia $^{(5)}$ en septiembre de 2007. En dicho Pleno, se sostuvo que:
"El juez, para expedir una medida cautelar antes o durante un proceso de violencia familiar debe considerar: la fundamentación fáctica y prueba anexa, que le permita evaluar la verosimilitud del derecho invocado y el peligro en la demora (requisitos generales de fondo, establecidos en el artículo 611 del Código Procesal Civil) para dictar la medida de protección o medida cautelar pudiendo prescindir de aquellos requerimientos formales que, eventualmente, constituyan una barrera a la tutela urgente que ameritan estas medidas, de conformidad con lo señalado en el artículo 3 inciso d) de la Ley de Violencia Familiar, concordante con el artículo 23 del mismo cuerpo legal".

(5) Pleno realizado con la intervención de las Cortes Superiores del Callao, Cañete, Lima y Lima Norte. 
Marianella Ledesma Narváez

De las afirmaciones que se hace en dicho Pleno, se advierte la tendencia a confundir medidas de protección con medidas anticipadas. Las primeras tienen un fin tuitivo y están contempladas expresamente en la Ley contra la Violencia Familiar, así como en la segunda parte del artículo 677 del $\mathrm{CPC}$, en cambio, las medidas anticipadas, cuyo fin inmediato no es la protección sino de alcanzar la eficacia de la decisión final, busca ejecutar de manera antelada la futura decisión final y requiere de la ejecución de una contracautela, así como de la casi certeza del derecho que se invoca y la necesidad impostergable de asumir dicha anticipación para la eficacia del derecho a definirse. Resaltamos la mirada no formalista que asume el Pleno Jurisdiccional de ese entonces, cuando sostiene, que:

"las medidas de protección pueden ser aplicadas por el juez que conoce de un hecho de violencia familiar, en cualquier proceso, de conformidad con el artículo 677 del $\mathrm{CPC}$, dado que con amplitud el legislador prevé que para asuntos de familia e intereses de niños y adolescentes (divorcio, patria potestad, régimen de visitas, tenencia, tutela, curatela) se pueda ordenar de manera inmediata aquellas medidas que se consideren oportunas para el cese de los actos que se consideren lesivos y no se debe derivar esta facultad protectora a un nuevo pedido o un nuevo trámite porque con ello se limitaría el derecho a la tutela jurisdiccional efectiva y el juez no estaría asumiendo su rol de garante de los derechos humanos"(6).

Si bien ambas medidas, la cautelar y la de protección, tienen varios elementos en común, como la temporalidad, la variabilidad y la urgencia; las medidas de protección, son asumidas como tutelas de prevención hacia la víctima, al margen que se logre demostrar o no la responsabilidad penal del supuesto agresor; son dos medidas diversas por más que ambas deriven de un supuesto de violencia, pues, se podría liberar al agresor de la condena penal por un tema de insuficiencia probatoria, pero ello no podría llevar a sostener que no se requiere una tutela de prevención a favor de la denunciante. Las medidas de protección juegan un rol muy importante en relación a la persona que ha promovido la denuncia, pues, puede haberse cancelado la punición, pero la tutela judicial seguirá y se mantendrá.

La tutela de prevención, se materializa a través de estas medidas de protección. Los sujetos beneficiados no son, en estricto, la parte actora, la que formula la denuncia sino incluso pueden ser personas ajenas a la denuncia pero que están unidas, por un vínculo familiar o por su pertenencia al mismo grupo familiar. Dicho en otras palabras, hay una serie de sujetos indeterminados que podrían ser beneficiados con este tipo de medidas de protección, cuyo objeto central es la prevención frente al riesgo latente que se puede atentar contra la integridad o la vida de quien viene a denunciar ser víctima de violencia en su entorno familiar.

A diferencia de la tutela anticipada, que está condicionada su vigencia a las resultas de la sentencia, en la tutela de prevención, su permanencia se justificará en tanto no se haya agotado con éxito la materialización de las medidas de tuición dictadas a favor de la persona que denuncia la agresión o maltrato. Evidentemente que para dictar estas medidas, la prueba que podría compulsar el juez, se relativizará. La mera alegación de quien invoca la violencia, es suficiente argumento para la medida de protección, con cargo a que luego el juez pueda reafirmar o levantar ésta, si verifica que las medidas de protección que en su momento dictó ya no justifica su permanencia; dicho en otras palabras, la mera alegación, activa la prevención, a diferencia de la tutela anticipada, que se requiere de una alta intensidad de la prueba que conlleve

(6) Sostiene el Pleno Jurisdiccional citado que la base legal, además del artículo 677 del CPC, se encuentra en el marco internacional e interamericano, como son la Convención Internacional para la eliminación de todas las formas de Discriminación contra la Mujer (CEDAW), así como la Convención Interamericana para la Protección de la Mujer en casos de Violencia o Convención de Belem do Pará. 
a asumir la alta probabilidad o la casi certeza de la existencia del derecho que alega la parte demandante.

Las medidas de protección no necesariamente deben estar condicionadas a plazos, sino al cumplimiento de resultados, al margen del tiempo en el que se pueda alcanzar ese resultado; en cambio, las medidas anticipadas, sí tienen un derrotero final, cual es, la sentencia que define la pretensión de la parte actora; para eso se constituyen, para hacer eficaz ese pronunciamiento final, pues, hay una alta evidencia del derecho que invoca la parte actora.

Es una tutela que se brinda en estricto a la actora, y con anticipación, situación que en el caso de las medidas de protección, no puede asumirse en esa dimensión, porque puede también ser extensiva a sujetos ajenos a la relación material del conflicto porque lo que se busca es proteger la integridad física y emocional de los integrantes del grupo familiar, al margen de la propia denunciante.

La instrumentalidad, como una característica propia de estas medidas anticipadas, no se extiende a las medidas de protección, pues, su objeto no es el derecho en litis, sino un bien jurídico colateral al debate, como es la integridad de la persona humana en toda su dimensión, de ahí que hemos dicho, no es una justificante para su dictado, la exigencia de medios de prueba que demuestren el riesgo para su supervivencia sino que la mera alegación es suficiente para materializar esa tutela. Ello evidentemente no es atendible en el caso de la tutela anticipada, pues, la evidencia del derecho, tiene que estar sustentada en una alta probabilidad de su existencia, para lo cual, la prueba que se muestre, es un referente crucial para sostener esa casi certeza en la existencia del derecho en debate. Expuesta así las ideas, pasaremos a analizar la necesidad de la vigencia de las medidas de protección, al margen de las resultas de la actividad del Ministerio Público o de la decisión judicial, expresada en la sentencia.

\section{La vigencia de las medidas de protección}

El artículo 23 de la Ley señala: "la vigencia de las medidas dictadas por el juzgado de familia o su equivalente se extiende hasta la sentencia emitida en el juzgado penal o hasta el pronunciamiento fiscal por el que se decida no presentar denuncia penal por resolución denegatoria, salvo que estos pronunciamientos sean impugnados". La redacción de este enunciado nos lleva a preguntarnos si un texto legal debe ser de mera aplicación o requiere ser sometido a una interpretación judicial para apreciar los alcances de este enunciado. Esta demás decir, a pesar del desarrollo del pensamiento jurídico, que los jueces han dejado de ser meros aplicadores de normas; han asumido que su actividad judicial descansa en la interpretación que se haga de una situación jurídica cuyos supuestos aparecen descritos en una norma, pero, que interpretada ésta en concordancia con todo un bagaje normativo que concurre al caso, privilegiemos en primer orden una interpretación conforme a las reglas y valores del marco constitucional.

Las medidas de protección deberían mantenerse al margen de las resultas de la actividad del Ministerio Público o de la responsabilidad penal del agresor, pues, a través de ellas se busca preservar a la persona humana, como eje de toda la arquitectura jurídica. Si hay el indicio que esta se encuentra en riesgo, todo el sistema de protección estatal se activa inmediatamente; la prevención tiene que mostrarse en toda su dimensión, pues, como dice el propio texto de la Carta Política, "la defensa de la persona humana y el respeto de su dignidad son el fin supremo de la sociedad y del Estado"(7).

Aún más, esa protección no solo es una carga para el Estado, quien debe velar por materializar mecanismos idóneos para su implementación, sino que también se constituye en un derecho de toda persona, que considere que está en riesgo su vida, su

(7) Véase Constitución Política del Perú, artículo 1. 
Marianella Ledesma Narváez

integridad moral, psíquica y física; pues, todo ello también se convierte en una limitante para alcanzar su libre desarrollo(8). El Estado no solo nos debe asegurar mecanismos de supervivencia y desarrollo sino que esa supervivencia tiene que ser en un escenario de tranquilidad, que permita que el individuo pueda desarrollar sus capacidades, sus talentos, su visión de vida, que en conjunción o coincidencia con otros talentos contribuyan a un desarrollo armónico de la vida social. Vivir en paz, con tranquilidad no es una aspiración sino un deber del Estado para crear los mecanismos necesarios para implementarla o derribar los elementos que la alteran ${ }^{(9)}$.

De ahí que como parte ese pacto social, se establece expresamente el deber de la comunidad y del Estado de proteger especialmente al niño, al adolescente, a la madre y al anciano en situación de abandono(10). Dicho en otras palabras, se debe dar una especial protección al grupo de personas que se encuentren en un estado vulnerable, para lo cual, la tuición se torna altamente necesaria. El binomio riesgo-prevención debe activarse con la simple alegación de ser víctima de violencia. En esta situación podemos también ubicar a la persona incapacitada para velar por sí misma a causa de una deficiencia física o mental; ahí con mayor razón, se intensifica la necesidad de afirmar su derecho al respeto de su dignidad y a un régimen legal de protección (...) y seguridad ${ }^{(11)}$.

La actividad tuitiva del Estado no solo se agota en una protección subjetiva, sino también se extiende a la exigencia de contar con un escenario de convivencia pacífica, de ahí que el propio texto del artículo 7 de la Constitución debe ser asumido como un deber y como un derecho, a la protección del medio familiar. Todo esto como parte del deber primordial del Estado de promover el bienestar general que se fundamenta en la justicia y en desarrollo integral y equilibrado de la Nación ${ }^{(12)}$.

El Tribunal Constitucional viene desarrollando un marco constitucional tutelar de la mujer, que busca remover y superar la posición desventajosa que históricamente ha ocupado. Además ha reafirmado la especial protección que merecen por parte del Estado aquellas personas que se encuentran en situación de vulnerabilidad, "dentro de la política estatal de salvaguardar a los más desprotegidos, en uno de los grupos de titulares superreforzados de derechos fundamentales o como también puede llamárseles titulares con una calidad especial" (STC 2006, 5). En ese contexto, se encuentran las personas adultas mayores, cuyos derechos ameritan por parte del Estado un deber especial de protección (STC 2014, 5-15). La lucha contra la violencia familiar y la protección de las víctimas de dicha violencia constituyen bienes constitucionales.

A todo lo expuesto hay que agregar la concordancia con instrumentos internacionales que apuntan a la tutela de prevención que debe implementar el Estado frente a grupos vulnerables como sería el caso de la mujer víctima de violencia en su entorno de familia.

En la Convención Interamericana para prevenir, sancionar y erradicar la violencia contra la mujer, Convención de Belem do Pará, encontramos las siguientes referencias a la protección de la mujer:

"Artículo 1: Toda mujer tiene derecho a una vida libre de violencia, tanto en el ámbito público como en el privado. (...)

Artículo 7: Los Estados Partes, entre los que se encuentra el Estado peruano, condenan todas las formas de violencia contra la mujer y convienen en adoptar, por todos los medios apropiados y sin dilaciones, políticas orientadas a prevenir, sancionar y erradicar dicha violencia y en llevar a cabo lo siguiente: (...)

(8) Véase Constitución Política del Perú, artículo 2, numeral 1.

(9) Véase Constitución Política del Perú artículo 2, numeral 22.

(10) Véase Constitución Política del Perú, artículo 6.

(11) Véase Constitución Política del Perú, artículo 7.

(12) Véase Constitución Política del Perú, artículo 44. 
La tutela de prevención en los procesos por violencia familiar Prevention guardianship in family violence processes

c. incluir en su legislación interna normas penales, civiles y administrativas, así como las de otra naturaleza que sean necesarias para prevenir, sancionar y erradicar la violencia contra la mujer y adoptar las medidas administrativas apropiadas que sean del caso;

d. adoptar medidas jurídicas para conminar al agresor a abstenerse de hostigar, intimidar, amenazar, dañar o poner en peligro la vida de la mujer de cualquier forma que atente contra su integridad o perjudique su propiedad; (...)

f. establecer procedimientos legales justos y eficaces para la mujer que haya sido sometida a violencia, que incluyan, entre otros, medidas de protección, un juicio oportuno y el acceso efectivo a tales procedimientos. (...)

Artículo 9: Para la adopción de las medidas a que se refiere este capítulo, los Estados Partes tendrán especialmente en cuenta la situación de vulnerabilidad a la violencia que pueda sufrir la mujer en razón, entre otras, de su raza o de su condición étnica, de migrante, refugiada o desplazada.

En igual sentido se considerará a la mujer que es objeto de violencia cuando está embarazada, es discapacitada, menor de edad, anciana, o está en situación socioeconómica desfavorable (...)".

En la Convención Americana sobre Derechos Humanos, tenemos lo siguiente:

"Artículo 17 [indica que]:

'1. La familia es el elemento natural y fundamental de la sociedad y debe ser protegida por la sociedad y el Estado'".

En cuanto a los menores, debe recordarse que según el artículo 19 de dicha Convención: "Todo niño tiene derecho a las medidas de protección que su condición de menor requieren por parte de su familia, de la sociedad y del Estado".

\section{Convención sobre Derechos del Niño}

"Artículo 19:

1. Los Estados Partes adoptarán todas las medidas legislativas, administrativas, sociales y educativas apropiadas para proteger al niño contra toda forma de perjuicio o abuso físico o mental, descuido o trato negligente, malos tratos o explotación, incluido el abuso sexual, mientras el niño se encuentre bajo la custodia de los padres, de un representante legal o de cualquier otra persona que lo tenga a su cargo.

2. Esas medidas de protección deberían comprender, según corresponda, procedimientos eficaces para el establecimiento de programas sociales con objeto de proporcionar la asistencia necesaria al niño y a quienes cuidan de él, así como para otras formas de prevención y para la identificación, notificación, remisión a una institución, investigación, tratamiento y observación ulterior de los casos antes descritos de malos tratos al niño y, según corresponda, la intervención judicial." (énfasis agregado).

Todo este marco constitucional y convencional nos lleva a asumir como interpretación conforme a la Constitución del artículo 23 de la Ley, que la vigencia de la medida de protección será determinada en cada caso, luego que el juez, haya escuchado al beneficiado con la medida y se afirme la necesidad de su permanencia. En caso se afirme la necesidad de ésta, comunicará al juez de familia de esa decisión a fin que se mantenga la tutela de prevención, para lo cual se activará su seguimiento y administración a través de un mecanismo no jurisdiccional, propio de un procedimiento no contencioso.

La escucha previa a la parte afectada con la decisión, es un derecho constitucional que ya tiene toda una regulación y tratamiento jurisprudencial, en el caso de los niños y adolescentes $^{(13)}$. Como consecuencia de ello, el juez penal o el fiscal en el caso comunicará

(13) Véase Código de Niños y Adolescentes, artículo 85. 
Marianella Ledesma Narváez

al juez de familia su decisión de mantener en vigencia dichas medidas.

La Ley no limita que la única oportunidad en la que se puede dictar medidas de protección sea estrictamente dentro de las setenta y dos horas de recibida la denuncia, ni tampoco el número de veces que se podría dictar. Perfectamente podrían ser variadas, con mayor o menor intensidad, según las circunstancias en la que se encuentre la persona protegida con dicha medida. Si la situación de riesgo se advierte que continua, a pesar que no ha logrado comprobar la responsabilidad penal del agresor, el juez dictará una nueva medida ad hoca esa situación, caso contrario, podría perfectamente dejar sin efecto los alcances de dicha medida de protección. La tendencia es mantenerla, pues, ésta se convierte en una alerta permanente para cualquier acto o intento de agresión futura; ya hay un antecedente que perfectamente podría contribuir a un mejor análisis del clima de violencia en la que se desarrollaría la potencial víctima.

El Informe Defensorial No. 173-2015-DP refiere que los casos de feminicidio, un sector de las victimas denunciaron con antelación la violencia familiar. Esto nos permite afirmar dos situaciones: (i) se requiere tener un adecuado sistema de protección a las víctimas y (ii) se requiere contar con un adecuado registro de ellas, a fin que se pueda tener una lectura global de la problemática y no lecturas fragmentadas de ella. Un estudio realizado por la Defensoría sobre el Feminicidio, concluye que la víctima denunció los hechos y acudió al sistema de administración de Justicia para solicitar protección y el cese de la violencia.

"En los casos de feminicidio, respecto de la existencia de las denuncias previas de violencia familiar, en 7 casos (24.1\%) las víctimas habían denunciado hechos previos de violencia familiar; mientras que en 20 casos (69\%) familiares directos, amistades y otros señalaron en sus respectivas manifestaciones, que las víctimas habrían sido sometías a hechos de violencia familiar previos al feminicidio" (Defensoría del Pueblo 2015, 123).

Esto significa que no es suficiente que se dicte medidas de protección sino que debe haber una adecuada implementación de ellas; ya una investigación periodística revela esta debilidad, al señalar que "El $60 \%$ de medidas de protección por violencia familiar se incumple" (Ortiz 2016). En cuanto al segundo aspecto, debemos apreciar que la Ley crea un Registro Único de Víctimas y Agresores, en el que se consignen los datos de la víctima y del agresor, la tipificación, las causas y consecuencias de la violencia, la existencia de denuncias anteriores ${ }^{(14)}$. La existencia de este Registro responde a dos requerimientos importantes en la política contra la violencia hacia las mujeres. En primer lugar, permite contar con una visión integral del caso concreto y brindar una respuesta adecuada a la decisión y necesidades de la víctima desde los diferentes actores que intervienen; y en segundo lugar, contribuye a la elaboración de un diagnóstico general sobre el fenómeno de la violencia de género (causa, características y consecuencias) y la respuesta del Estado, posibilitando generar o modificar políticas, programas o intervenciones (Defensoría del Pueblo 2016, 108).

Con estos antecedentes, podríamos sostener que una interpretación que podría hacerse del artículo 23 de la Ley, es que solamente cesaría esta tutela de prevención, en la medida que se advierta que no esté en riesgo el objeto de protección. Recurrir al mecanismo de la escucha previa a la parte beneficiada con la medida, que luego se busca dejar sin efecto, se justifica en atención a que los instrumentos procesales deben buscar adecuar la formalidad al logro de los objetivos de este proceso especial; para lo cual los jueces deben asumir rol de verificación permanente a fin de contrastar si dichas medidas de protección han cumplido su finalidad; en tanto no se logre evidenciar ello, la posibilidad del riesgo justificaría su vigencia.

El interés superior de la víctima es la razón de ser de este procedimiento que busca salvaguardar desde el inicio del procedimiento, más allá de meras apreciaciones literales de la norma, para lo cual, el propio legislador

(14) Véase Ley 30364, artículo 42. 
ha establecido que toda norma de la Ley tiene que ser interpretada bajo determinados principios rectores que deben regir no solo en la interpretación, sino en la aplicación de la Ley. Dicho en otras palabras, la interpretación del artículo 23 de la Ley tiene que ajustarse a determinados principios, como el de intervención inmediata y oportuna; la sencillez y oralidad; y la razonabilidad y proporcionalidad.

El artículo 2, numeral 4 de la Ley dice que "los operadores de justicia, ante un hecho o amenaza de violencia, deben actuar en forma oportuna, sin dilaciones por razones procedimentales, formales o de otra naturaleza, disponiendo el ejercicio de las medidas de protección previstas en esta ley y otras normas, con la finalidad de atender efectivamente a la víctima". Entonces, si esto es un criterio rector, porque no conjugar la lectura del artículo 23 de la Ley, con la necesaria escucha a la parte beneficiada con las medidas de protección, a fin de verificar la necesidad de esta o no, e incluso la intensidad de su permanencia si fuere el caso.

Podríamos remitirnos al Código de Niños y Adolescentes en el que expresamente se señala que el juez debe escuchar la opinión del niño en los procesos de tenencia; todo ello con la finalidad de atender en mejor forma, a la persona que ha denunciado ser víctima de violencia. Hay que recordar que la propia Ley crea ese escenario cuando en el artículo 13 señala que "las denuncias por actos de violencia contra las mujeres y los integrantes del grupo familiar se regulan por las normas previstas en la presente ley y, de manera supletoria, por (...) el código de los niños y adolescentes".

Para complementar este análisis, recurrimos a otro principio rector que la propia ley invoca se considere en su interpretación. Es el principio de sencillez y oralidad. "Todos los procesos por violencia contra las mujeres y los integrantes del grupo familiar se desarrollan considerando el mínimo de formalismo (...)" por tanto ante la necesidad de mantener dichas medidas de protección, estas perfectamente podrían direccionar su administración y tratamiento a través de un procedimiento no contencioso. El inciso 12 del artículo 749 CPC, dice: "Se tramitan en proceso no contencioso los siguientes asuntos: (...) Las solicitudes que, a pedido del interesado y por decisión del juez, carezcan de contención". Esto significaría que la vigencia de las medidas de protección perfectamente podría ser monitoreada o administrada por el juez de familia a través de este procedimiento.
Otro principio rector que la propia Ley consagra para su interpretación, es el principio de razonabilidad y proporcionalidad. El artículo 2, numeral 6 dice que el fiscal o juez a cargo de cualquier proceso de violencia, debe ponderar la proporcionalidad entre la eventual afectación causada y las medidas de protección y de rehabilitación a adoptarse; por tanto, bajo esa ponderación, si el propio juez o fiscal advierte que la denunciante estaría bajo riesgo de ser violentada, deberían estas mantenerse. El propio texto de este principio rector considera que se debe hacer un juicio de razonabilidad de acuerdo con las circunstancias del caso, emitiendo decisiones que permitan proteger efectivamente la vida, la salud y la dignidad de las víctimas. Como señala este principio, la violencia no surge en un instante, es el resultado de todo un desarrollo, de una evolución, que en esa dinámica se agota en la fase de explosión, con violencia, afectando bienes jurídicos; precisamente lo que se debe buscar es evitar su desarrollo, de ahí que se hace especial referencia, a que las medidas que se dicten deberían adecuarse a las fases del ciclo de la violencia y a las diversas tipologías que representa la violencia contra las mujeres y los integrantes del grupo familiar.

Precisamente, el Informe Defensorial No. 1732015-DP hace referencia a esta dinámica previa, "el $81 \%$ del total de tentativas de feminicidios, las propias víctimas sobrevivientes a la violencia señalaron que hubo amenazas previas por parte de los agresores de estos hechos" (Defensoría del Pueblo 2015, 196). Además dicho Informe Defensorial precisa que en el $28 \%$ del total de expedientes de feminicidio íntimo y tentativa analizados, las víctimas acudieron a los servicios estatales para denunciar los hechos de violencia que venían sufriendo, sin embargo, debido a la falta de una respuesta efectiva por parte de estos servicios, sus vidas continuaron en riesgo, siendo que la mitad de ellas, terminaron cruelmente asesinadas (Defensoría del Pueblo 2015, 197). 


\section{Tratamiento de las medidas de protección fuera de los alcances del proceso penal}

Según el Informe Defensorial No. 173-2015-DP, "en el 50\% de los casos de feminicidio íntimo y tentativa, se identificó que las víctimas vivían con el agresor al momento de los hechos (conviviente o cónyuges). Esta realidad evidencia la situación de mayor riesgo y vulnerabilidad a la que se enfrentan las víctimas de violencia" (Defensoría del Pueblo 2015, 196), de ahí que es importante mirar los casos de violencia familiar con la máxima cautela a fin de preservar en medidas de tuición efectivas para las víctimas. Si un juez interpretando el artículo 23 de la Ley considerase que esta debe seguir vigente, más allá de haber concluido cualquier actividad vinculada con la denuncia penal, luego de haber agotado su escucha en una audiencia oral, la vigencia de la medida será decidida por estos para lo cual comunicará al juez de familia, quien dictó la medida de protección, para que proceda a administrar los términos y condiciones de ésta. Esto implica generar un procedimiento para ello, para lo cual, nos remitimos a lo regulado en el CPC.

El artículo 749 CPC, inciso 12, permitiría la continuación de la tutela a favor de la víctima. Textualmente, dice: Se tramitan en proceso no contencioso los siguientes asuntos: Las solicitudes que a pedido del juez carezcan de contención. Estamos ante un proceso sin contención que no tendrá como objetivo central un conflicto potencial de intereses. Algunos autores lo califican como un procedimiento de jurisdicción voluntaria. Este no es un tema pacífico en la doctrina, Carnelutti lo califica como un caso de jurisdicción especial, pues la jurisdicción no solo sirve para resolver conflictos, sino también para evitarlos o prevenirlos. Para Monroy:

“(...) la llamada jurisdicción voluntaria supone, desde la óptica histórica, la asunción de actividades que no son jurisdiccionales, entendido este concepto en su acepción estricta. Sin embargo, reconocemos la existencia de una actividad jurisdiccional que sin ser notoriamente contenciosa cumple una función preventiva $y$, en ese contexto, los antecedentes de una distorsión histórica -que no es otra cosa que el concepto de jurisdicción voluntaria- bien podrían utilizarse como cauce para esta otra finalidad (preventiva) de la jurisdicción, cuya importancia contemporánea es considerable" (Monroy 1996, 244).
El proceso no contencioso no tiene partes en sentido estricto, pues ella es una noción que implica enfrentamiento entre dos sujetos, por tanto solo es aplicable a los procesos contenciosos. En este tipo de procesos corresponde reemplazar el concepto parte por el de peticionario, a quien se califica como la persona que en nombre propio o en cuyo nombre se reclama la emisión de un pronunciamiento judicial que constituya, integre o acuerde eficacia a determinado estado o relación jurídica privada. El peticionante o pretensor no pide nada contra nadie, pues no hay adversarios, por tanto, no es parte porque no es contraparte de nadie, por lo cual, uno de los efectos de estas declaraciones es que no generan cosa juzgada, ni aun por haber sido objeto de recurso de apelación y hayan sido confirmadas por los jueces superiores. Para Couture, en estos procesos los jueces no juzgan ni prejuzgan:

"se limitan a fiscalizar si lo que ha afirmado el peticionante es en primer orden cierto, con arreglo a la justificación que el mismo suministra. Es una tarea de simple verificación externa, unilateral, formal. A diferencia de la sentencia jurisdiccional cuyo contenido puede ser declarativo, constitutivo, de condena o cautelar, las decisiones que se profieren en la jurisdicción voluntaria son siempre de mera declaración, ni condenan ni constituyen nuevos derechos. En la jurisdicción voluntaria, por el contrario, no es el peligro en la demora lo que se trata de evitar, sino la incertidumbre, la falta de una documentación adecuada, el carácter equívoco del derecho, o en otros casos, una garantía requerida por la ley".

La jurisdicción ordinaria contenciosa y la voluntaria son diferenciadas por Devis Echandía bajo los siguientes términos:

"En la voluntaria los interesados que inician el proceso persiguen determinados efectos jurídicos materiales para ellos mismos, en la contenciosa los demandantes buscan también producir efectos sustanciales 
La tutela de prevención en los procesos por violencia familiar

Prevention guardianship in family violence processes

obligatorios y vinculantes para determinados demandados; en la contenciosa el juez decide entre los litigantes, en la voluntaria se pronuncia solo respecto del peticionario; en el proceso de jurisdicción voluntaria no existe demandado, sino simple interesado peticionario, al paso que en el contencioso existe siempre un demandado; en la voluntaria se persigue dar certeza o precisión a un derecho o legalidad a un acto, o ciertos efectos jurídicos materiales, sin presentarle al juez inicialmente ninguna controversia ni litigio para su solución en la sentencia, ni siquiera pedirle una declaración contra otra persona, en la contenciosa, por el contrario, inicialmente se le está pidiendo la solución de un litigio con el demandado, o al menos una declaración que vincule y obligue a este; en la contenciosa es normal que la sentencia tenga el valor de cosa juzgada, si decide en el fondo, en cambio en la voluntaria jamás constituye cosa juzgada" (Devis 1984, 86).

\section{Conclusiones}

a) La mejor respuesta que se brinde a la parte afectada en un proceso de violencia familiar será la que afirme las medidas de tuición a favor de la víctima y de los integrantes del grupo familiar violentado. Esto significa que la tutela judicial no solo debe estar orientada a materializar la punición o el resarcimiento en los casos de violencia; todo lo contrario, hay la necesidad de afirmar la tutela de prevención, a través de las medidas de protección.

b) El artículo 23 de la Ley, debe ser interpretado bajo parámetros constitucionales y no de simple legalidad, para afirmar lo siguiente:

b.1. No se puede equiparar los alcances de una medida de protección a la de una medida cautelar. Las medidas de protección seguirán vigentes, en tanto no haya desaparecido las condiciones de riesgo de la denunciante. b.2. No se puede trasladar las categorías procesales propias de la tutela resarcitoria o de punición, a tutelas meramente preventivas o de tuición. Su escenario, será de no contienda, sino de tuición a la víctima.

b.3. La tutela preventiva, a partir de las medidas de protección, debe entenderse como una actividad judicial no jurisdiccional, unilateral, que no genera cosa juzgada.

c) Para abordar los temas de violencia familiar se requiere de jueces altamente activistas, que se comprometan con la tutela de prevención, al margen de la existencia o no del proceso penal. La naturaleza de la problemática así lo exige, por ello, cuando una o más personas se encuentren en un estado vulnerable, la tuición se torna altamente necesaria. El binomio riesgo-prevención debe activarse con la simple alegación de ser víctima de violencia.

\section{Referencias bibliográficas}

Defensoría del Pueblo. 2015. Informe No 173-2015-DP, "Feminicidio Íntimo en el Perú: Análisis de expedientes judiciales (2012-2015)". Octavo Reporte de la Defensoría del Pueblo sobre el cumplimiento de la Ley de Igualdad de Oportunidades entre Mujeres y Hombres. Perú: Defensoría del Pueblo.

2016. Informe de Adjuntía No 003-2016-DP/ADM, Derecho a la Salud de las mujeres víctimas de violencia sexual. Seguimiento de las recomendaciones defensoriales en establecimientos de salud en Arequipa, Junín, Lima, Piura y Puno. Defensoría del Pueblo.

Devis Echandía, Hernando. 1984. Teoría general del proceso. Tomo I. Buenos Aires: Editorial Universidad.

Monroy Gálvez, Juan. 1996. Introducción al proceso civil. Tomo I. Santa Fe de Bogotá: Temis - De Belaunde \& Monroy Editores.

Ortiz, Walter. 2016. El $60 \%$ de medidas de protección por violencia familiar se incumple. La República, 14 de setiembre, sección Sociedad.

Tribunal Constitucional. 2006. Expediente No. 07873-2006-PCLTC.

Tribunal Constitucional. 2014. Expediente No. 05157-2014-PALTC. 